\title{
Analytical Predictor-Corrector Guidance Algorithm Based on Drag Modulation Flight Control System for Mars Aerocapture
}

\author{
Yu-ming Peng $\mathbb{D}^{1,}{ }^{1,2}$ Bo Xu, ${ }^{1}$ Bao-dong Fang, ${ }^{3}$ and Han-lun Lei ${ }^{1}$ \\ ${ }^{1}$ School of Astronomy and Space Science, Nanjing University, Nanjing, China \\ ${ }^{2}$ Shanghai Institute of Satellite Engineering, Shanghai, China \\ ${ }^{3}$ Shanghai Key Laboratory of Deep Space Exploration Technology, Shanghai, China \\ Correspondence should be addressed to Yu-ming Peng; nuaapym@qq.com
}

Received 5 September 2017; Revised 10 December 2017; Accepted 20 December 2017; Published 19 March 2018

Academic Editor: Christopher J. Damaren

Copyright (C) 2018 Yu-ming Peng et al. This is an open access article distributed under the Creative Commons Attribution License, which permits unrestricted use, distribution, and reproduction in any medium, provided the original work is properly cited.

Aerocapture is one of the essential technologies for future large-scale space exploration missions, as it can significantly reduce the $\Delta v$ and fuel requirement. The performance and robustness of two different aerocapture control methods are analyzed around Mars exploration, and then an analytic predictor-corrector guidance algorithm for drag modulation flight control system is proposed. A piecewise linear function between velocity and flight path angle is established by appropriate approximations and assumptions, and then the state at atmosphere interface can be predicted by an analytical method; therefore, aerocapture guidance can be realized by feedback control. Numerical simulation is used to evaluate performance and robustness of the algorithm. The simulation results show that the guidance algorithm is accurate and robust, which can effectively overcome the influence of atmospheric density error, aerodynamic parameter error, and initial state uncertainty.

\section{Introduction}

For a planetary orbital mission, the probe must implement a series of maneuvers to ensure that the probe is captured and becomes an orbiter when arriving at the target. The requirement of velocity reduction has been an important constraint, and the probe must carry so much propellant that limits the dry weight of it. Therefore, it is one of the problems on how to save the propellant and enter the target orbit quickly and accurately. Aerocapture is an effective way to solve the problem above [1-3]. The fundamental principle of aerocapture is to reduce the velocity by utilizing the aerodynamic drag effectively when crossing the planet's atmosphere, and only a small amount of propellant is needed for achieving the target orbit. As shown in Figure 1, the probe enters the atmosphere along the hyperbolic orbit and then slows down thanks to aerobraking. If the velocity decrement is appropriate, the probe will fly out of the atmosphere and be an orbiter, but when the perigee is still below the atmosphere at the moment, a correction maneuver must be carried out to raise the perigee when arriving at the apogee. The precise control of the velocity decrement is crucial for aerocapture.
Guidance is one of the significant factors in achieving aerocapture. The guidance algorithm of aerocapture is related to the control variables. In general, the state variables that can be adjusted include lift and drag; correspondingly, there are two kinds control modes: lift modulation mode and drag modulation mode. The first one is to correct the flight trajectory by adjusting the lift direction. In this way, the probe must be able to generate a lift during flight; it is generally using a centroid offset blunt-cone configuration like Mars Science Laboratory [4], as shown in Figure 2. Here, the bank angle is defined as the angle of rotation around the velocity vector.

Another way is to adjust the drag by changing the reference area of the probe, such as hypersonic inflatable aerodynamic devices (HIADs) [5-8]. In order to control the velocity decrement, the probe may need to increase or decrease the reference area when captured trajectory deviates from a predetermined trajectory [9], as shown in Figure 3.

Up to now, a variety of aerocapture guidance algorithms has been developed for the lift modulation flight control system, such as the analytical predictor-corrector (APC) [10-14], the energy controller (EC) [15], the numerical predictor-corrector (NPC) [16], and the terminal point 


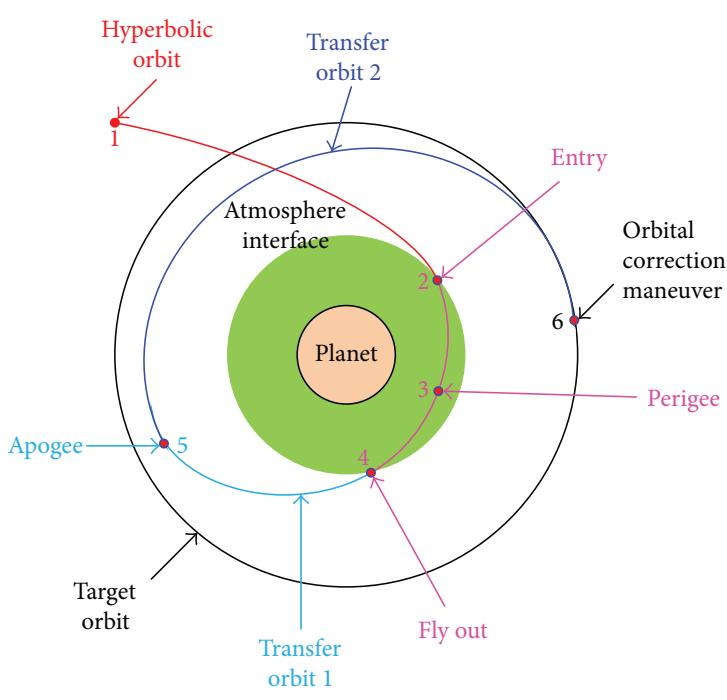

Figure 1: Aerocapture for the planet.

controller (TPC) $[12,17]$. Through the comparison of these algorithms, it is found that APC has certain advantages in precision, complexity, and robustness [18].

Medlock and Gates have studied the theory and applications of ballute aerocapture and proposed a dual-use ballute system for the exploration of the solar system [19]. Putnam and Braun proposed the concept of the drag modulation flight control system and analyzed the guidance performance using NPC [9]. For the drag modulation flight control system, the current guidance algorithm research mainly focuses on NPC. It relies on the accuracy of the atmospheric density model, and its computational complexity is very high which limits its application. Aiming at the shortcomings of the numerical predictor-corrector algorithm, this paper presents an analytical predictive guidance algorithm for the drag modulation flight control system which can overcome the above disadvantages and make it possible for engineering applications.

\section{Dynamic Equation}

The probe is modeled as a rigid body flying in a stationary atmosphere of a nonrotating planet which is assumed to be a uniform sphere. The $3 \mathrm{DOF}$ equations of motion are given as follows [10]:

$$
\begin{aligned}
\dot{r} & =v \sin \gamma, \\
\dot{\theta} & =\frac{v \cos \gamma \sin \psi}{r \cos \lambda}, \\
\dot{\lambda} & =\frac{v}{r} \cos \gamma \cos \psi, \\
\dot{v} & =-D-g \sin \gamma, \\
\dot{\gamma} & =\left(\frac{v}{r}-\frac{g}{v}\right) \cos \gamma+\frac{L \cos \phi}{v}, \\
\dot{\psi} & =\frac{v}{r} \cos \gamma \sin \psi \tan \lambda+\frac{L \sin \phi}{v \cos \gamma},
\end{aligned}
$$

where $r, \theta, \lambda, v, \gamma, \psi$, and $\phi$ are the radius, longitude, latitude, velocity, flight path angle, heading angle, and bank angle, respectively, $D$ is the drag acceleration, and $L$ is the lift acceleration, defined in

$$
\begin{aligned}
& L=\frac{0.5 \rho v^{2} C_{L} S}{m}, \\
& D=\frac{0.5 \rho v^{2} C_{D} S}{m}=\frac{0.5 \rho v^{2}}{\beta},
\end{aligned}
$$

where $C_{D}$ is the drag coefficient, $C_{L}$ is the lift coefficient, $S$ is the reference area, $m$ is the mass of the probe, and $\beta=m /\left(C_{D} S\right)$ is the ballistic coefficient.

A scale height exponential density profile is used to compute the atmospheric density $\rho$ at the height relative to the surface $h$.

$$
\rho=\rho_{0} \mathrm{e}^{-\left(h / h_{s}\right)},
$$

where $\rho_{0}$ is the atmospheric density at the surface and $h_{s}$ is the scale height. The gravity acceleration can be modeled with sufficient accuracy using standard gravity models [10].

$$
g=\frac{\mu}{r^{2}}
$$

For the lift modulation flight control system, the ballistic coefficient $\beta$ can be assumed to be constant, and the bank angle $\phi$ is the unique control variable. For the drag modulation flight control system, it is assumed that the probe is always flying close to a 0 -degree angle of attack; in other words, there is no lift. The variable that can control the probe is the ballistic coefficient, which contains the drag coefficient and the reference area.

\section{Guidance Law}

3.1. Lift Modulation. The analytical predictor-corrector guidance algorithm based on lift modulation has been presented in $[7,9]$. This algorithm uses an analytical solution to predict the atmosphere exit conditions. The algorithm contains two phases: the equilibrium glide phase and the exit phase.

3.1.1. Equilibrium Glide Phase. Because of the low atmospheric density at the initial phase, the lift is very small and the control variable is easily saturated. Therefore, the bank angle is usually stabilized at $0 \mathrm{deg}$. The main motion characteristic of the probe in the equilibrium glide state is that the flight path angle is near zero and the altitude change rate is maintained in a small range. The primary purpose at the equilibrium glide phase is to reduce the velocity by aerodynamic drag. The derivative of the flight path angle $\dot{\gamma}$ is set to zero.

$$
\left(\frac{v^{2}}{r}-g\right)+L \cos \phi=0 .
$$

Then the equilibrium glide state corresponding to the bank angle can be described as

$$
\cos \phi_{\mathrm{eq}}=\frac{m}{C_{L} q S}\left(g-\frac{v^{2}}{r}\right) .
$$




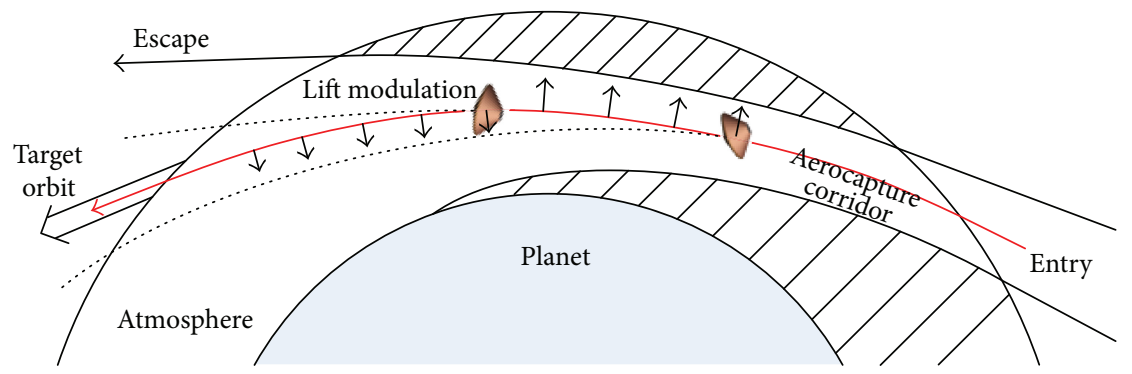

(a)

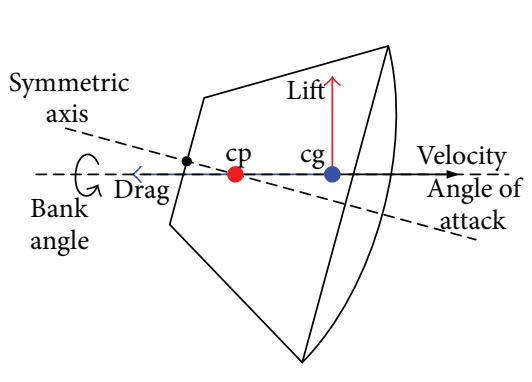

(b)

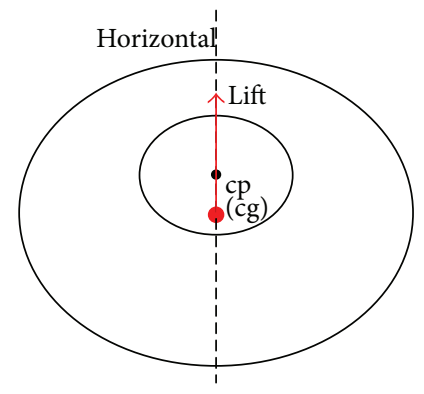

(c)

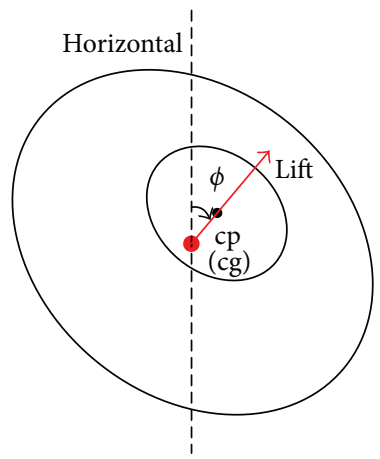

(d)

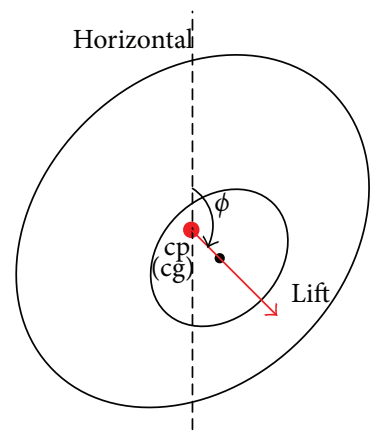

(e)

FIGURE 2: Lift modulation flight control system for planet aerocapture ((c), (d), and (e) are the views from velocity direction).
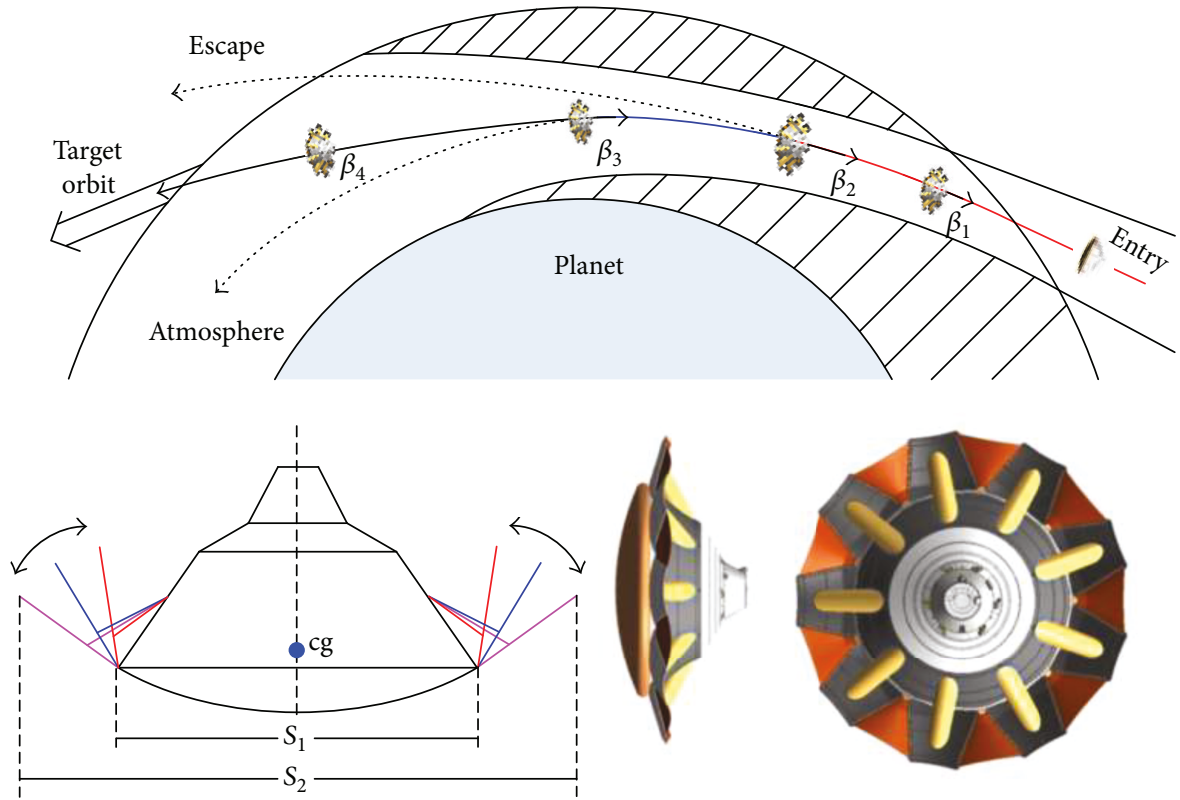

FIGURE 3: Drag modulation flight control system for planet aerocapture.

The dynamic pressure can be expressed as

$$
q_{\mathrm{eq}}=\frac{1}{\cos \phi_{\mathrm{eq}}} \frac{m}{C_{L} S}\left(g-\frac{v^{2}}{r}\right)=K \frac{m}{C_{L} S}\left(g-\frac{v^{2}}{r}\right),
$$

where $K$ is the factor which indicates the lift margin at the equilibrium glide state; the reference drag acceleration profile is shown below:

$$
D_{\mathrm{eq}}=K \frac{C_{D}}{C_{L}}\left(\frac{v^{2}}{r}-g\right) .
$$

Just only controlling the bank angle tracking reference drag can maintain the equilibrium glide state; the bank angle command can be calculated by the following:

$$
\cos \phi_{\mathrm{cmd}}=\cos \phi_{\mathrm{eq}}-G_{h 1} \dot{h}+G_{d 1}\left(D-D_{\mathrm{ref}}\right)
$$




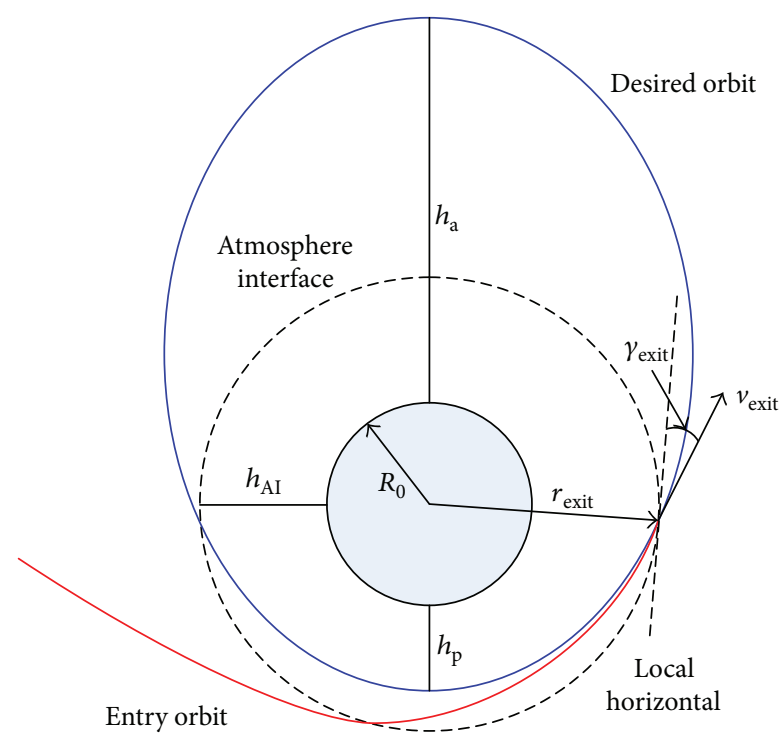

Figure 4: Orbit after aerocapture.

where $\phi_{\mathrm{cmd}}$ is the command bank angle and $G_{h 1}$ and $G_{d 1}$ are the gain factors.

3.1.2. Exit Phase. When the velocity reaches a certain threshold, it switches to exit the guidance algorithm. The algorithm determines the reference derivative of the height $\dot{h}_{\text {ref }}$ according to the target orbit apogee height and controls the probe to track it. Thus, the form of the command bank angle is as follows:

$$
\cos \phi_{\mathrm{cmd}}=\cos \phi_{\mathrm{eq}}-G_{h 2}\left(\dot{h}-\dot{h}_{\mathrm{ref}}\right)-G_{d 2}\left(D-D_{\mathrm{ref}}\right) .
$$

In order to calculate the reference altitude change rate $\dot{h}_{\text {ref }}$, it is necessary to obtain the velocity loss due to aerodynamic drag first

$$
\Delta v_{\text {aero }}=-\frac{1}{1 / v+\dot{h}_{\text {ref }} / h_{\mathrm{s}} D} .
$$

The velocity when exiting the atmosphere can be computed coupled with the effect of gravity.

$$
v_{\text {exit }}=\sqrt{v^{2}+2 \mu\left(\frac{1}{r_{\text {exit }}}-\frac{1}{r}\right)}+\Delta v_{\text {aero }}
$$

where $r_{\text {exit }}$ is the radial distance from the center of Mars to the atmosphere interface. If assumed that the vertical acceleration is constant, the vertical velocity at the atmosphere interface can be obtained:

$$
v_{r_{\text {exit }}}=\sqrt{\dot{h}_{\text {ref }}^{2}-2\left(\frac{v_{\text {exit }}^{2}}{r_{\text {exit }}}-\frac{\mu}{r_{\text {exit }}^{2}}\right)\left(r-r_{\text {exit }}\right)} .
$$

Further, the desired exit velocity can be obtained according to the height of the center of the target orbit.

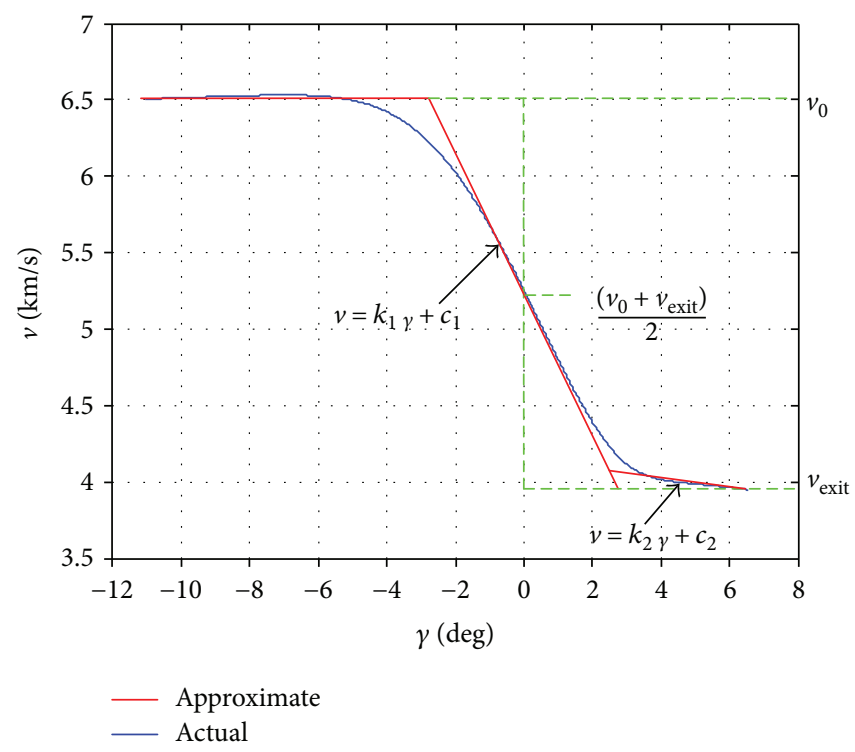

Figure 5: The correlation between velocity and flight path angle.

$$
v_{\text {desired }}=\sqrt{\frac{v_{r_{\text {exit }}^{2}}^{2}+2 \mu\left(r_{\mathrm{a}}^{2} / r_{\text {exit }}^{2}\right)\left(1 / r_{\mathrm{a}}-1 / r_{\text {exit }}\right)}{\left(1-r_{\mathrm{a}}^{2} / r_{\text {exit }}^{2}\right)}},
$$

where $r_{\mathrm{a}}$ is the apogee radius of the target orbit. In summary, the reference derivative of the height $\dot{h}_{\text {ref }}$ can be obtained by multiple iterations.

$$
\dot{h}_{\text {ref }}(k+1)=\dot{h}_{\text {ref }}(k)-\frac{v_{\text {desired }}-v_{\text {exit }}}{\partial v_{\text {desired }} / \partial \dot{h}_{\text {ref }}-\partial v_{\text {exit }} / \partial \dot{h}_{\text {ref }}},
$$

where

$$
\begin{aligned}
\frac{\partial v_{\text {desired }}}{\partial \dot{h}_{\text {ref }}} & =\frac{\Delta v_{\text {aero }}^{2}}{h_{\mathrm{s}} d}, \\
\frac{\partial v_{\text {exit }}}{\partial \dot{h}_{\text {ref }}} & =\frac{\dot{h}_{\text {ref }}}{v_{\text {desired }}\left(1-r_{\mathrm{a}}^{2} / r_{\text {exit }}^{2}\right)} .
\end{aligned}
$$

3.2. Drag Modulation. It is not difficult to find from the previous analysis that the core idea of the lift modulation guidance algorithm is to assume that the altitude change rate is constant during the exit phase and the altitude change rate can be predicted based on the target orbit and the current state, and then it only need to control the bank angle to track the reference altitude change rate. With reference to this idea, it is necessary to find some parameters which are related to the target orbit, and this relationship can be expressed as an analytic function. It is found that the velocity is correlated with the flight path angle when the probe is flying with a fixed ballistic coefficient.

It can be seen that the velocity and the flight path angle are approximately linear and can be approximated by a piecewise linear function as follows: 


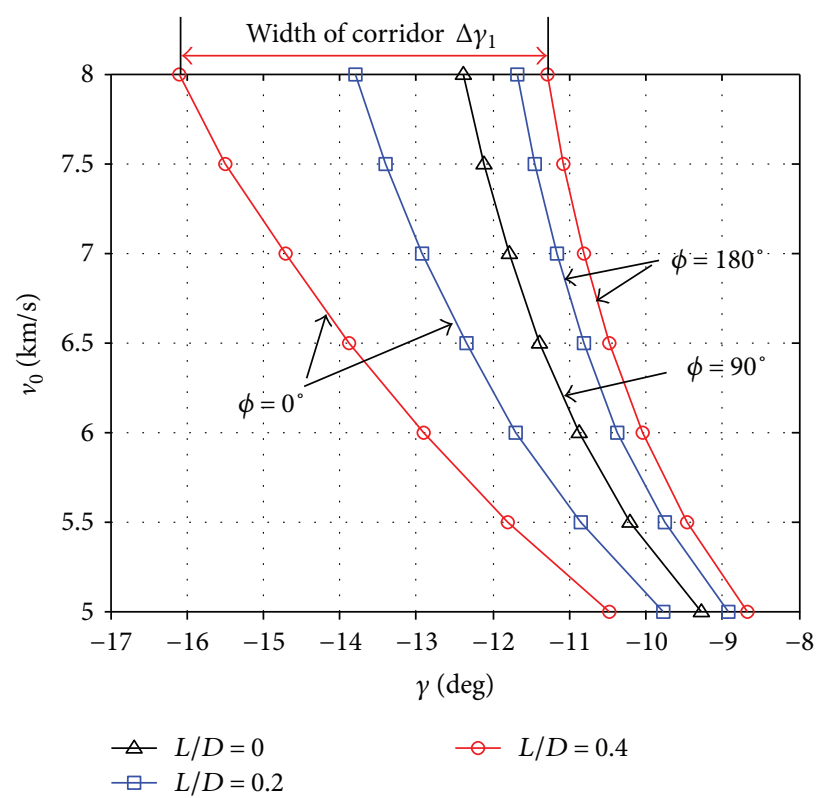

(a) Lift modulation

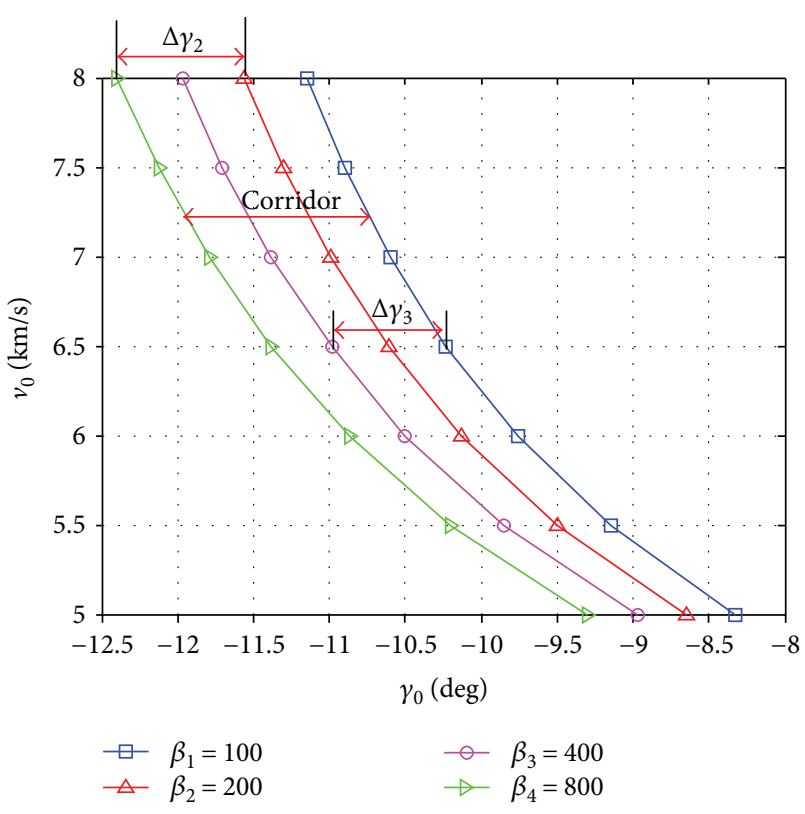

(b) Drag modulation

FIGURE 6: Aerocapture corridor of lift modulation and drag modulation.

TABLE 1: Initial state and parameters for Monte Carlo simulation.

\begin{tabular}{lccc}
\hline Parameters & Nominal & Error & $\begin{array}{c}\text { Distribution } \\
\text { type }\end{array}$ \\
\hline Initial velocity $v_{0}$ & $6.5 \mathrm{~km} / \mathrm{s}$ & $\pm 20 \mathrm{~m} / \mathrm{s}$ & Gaussian \\
Initial radius $r_{0}$ & $3522 \mathrm{~km}$ & $\pm 1 \mathrm{~km}$ & Gaussian \\
Initial FPA $\gamma_{0}$ & $-11 \mathrm{deg}$ & $\pm 0.1^{\circ}$ & Gaussian \\
Initial longitude $\theta_{0}$ & $5 \mathrm{deg}, \mathrm{E}$ & $\pm 0.05^{\circ}$ & Gaussian \\
Initial latitude $\lambda_{0}$ & $5 \mathrm{deg}, \mathrm{N}$ & $\pm 0.05^{\circ}$ & Gaussian \\
Initial heading angle $\psi_{0}$ & $20 \mathrm{deg}$ & $\pm 0.05^{\circ}$ & Gaussian \\
Ballistic coefficient $\beta_{\min }$ & $100 \mathrm{~kg} / \mathrm{m}^{2}$ & $\pm 10 \%$ & Gaussian \\
Ballistic coefficient $\beta_{\max }$ & $800 \mathrm{~kg} / \mathrm{m}^{2}$ & $\pm 10 \%$ & Gaussian \\
Initial bank angle $\phi_{0}$ & $0 \mathrm{deg}$ & - & - \\
Initial mass $m_{0}$ & $8000 \mathrm{~kg}$ & - & - \\
Perigee altitude $h_{\mathrm{p}}$ & $3000 \mathrm{~km}$ & - & - \\
Apogee height $h_{\mathrm{a}}$ & $35 \mathrm{~km}$ & - & - \\
Atmosphere interface & $125 \mathrm{~km}$ & - & - \\
$h_{\text {interface }}$ & & & - \\
\hline
\end{tabular}

$$
v= \begin{cases}v_{0}, & \gamma \leq \gamma_{s 1}, \\ k_{v 1} \gamma+c_{v 1}, & \gamma_{s 2}<\gamma \leq \gamma_{s 1}, \\ k_{v 2} \gamma+c_{v 2}, & \gamma>\gamma_{s 2} .\end{cases}
$$

In this condition, the current velocity and drag acceleration can be reversed according to the exit velocity $v_{\text {exit }}$ and exit flight path angle $\gamma_{\text {exit }}$, and then the required ballistic coefficient can be determined. The perigee and apogee heights after aerocapture are $h_{\mathrm{p}}$ and $h_{\mathrm{a}}$, respectively (see Figure 4 ).

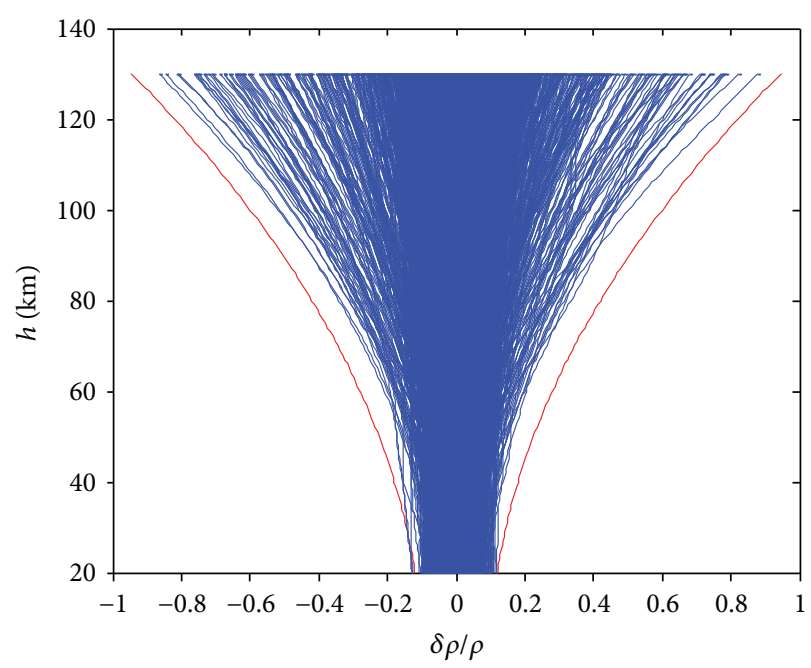

FIGURE 7: Uncertainty error of atmospheric density.

According to the orbital dynamics equation, the target orbit parameters can be calculated as follows:

$$
\begin{aligned}
a_{\text {exit }} & =\frac{h_{\mathrm{a}}+h_{\mathrm{p}}+2 R_{0}}{2}, \\
e_{\text {exit }} & =\frac{h_{\mathrm{a}}-h_{\mathrm{p}}}{h_{\mathrm{a}}+h_{\mathrm{p}}} \\
H_{\text {exit }} & =\sqrt{\mu \cdot a\left(1-e_{\text {exit }}^{2}\right)}, \\
E_{\text {exit }} & =\frac{-\mu}{2 a_{\text {exit }}},
\end{aligned}
$$

where $a_{\text {exit }}, e_{\text {exit }}, H_{\text {exit }}$, and $E_{\text {exit }}$ are semimajor axis, eccentricity, orbital angular momentum, and orbital energy, 


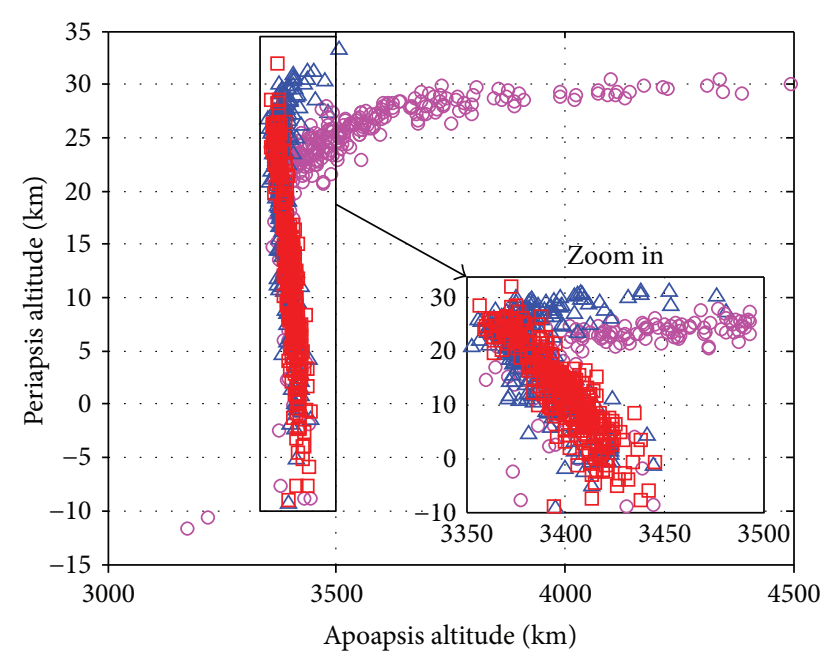

$$
\begin{aligned}
& \triangle L / D=0.2 \\
& \triangle L / D=0.3 \\
& \square L / D=0.4
\end{aligned}
$$

Figure 8: Distribution of perigee and apogee after aerocapture.

respectively, and $R_{0}$ is the average radius of Mars. Furthermore, the radius, velocity, and flight path angle at the atmosphere interface can be calculated:

$$
\begin{aligned}
& r_{\text {exit }}=R_{0}+h_{\text {interface }} \\
& v_{\text {exit }}=\sqrt{2\left(\frac{\mu}{r_{\text {exit }}}+E_{\text {exit }}\right)}, \\
& \gamma_{\text {exit }}=\frac{\pi}{2}-\arcsin \left(\frac{H_{\text {exit }}}{r_{\text {exit }} v_{\text {exit }}}\right) .
\end{aligned}
$$

The derivative of (17) is

$$
\begin{aligned}
\dot{v}_{\text {ref }}= & -D_{\text {ref }}-g \sin \gamma=k_{v} \dot{\gamma} \\
& = \begin{cases}0, & \gamma<\gamma_{s 1}, \\
k_{v 1}\left(\left(\frac{v}{r}-\frac{g}{v}\right) \cos \gamma\right), & \gamma_{s 2}<\gamma<\gamma_{s 1}, \\
k_{v 2}\left(\left(\frac{v}{r}-\frac{g}{v}\right) \cos \gamma\right), & \gamma>\gamma_{s 2},\end{cases} \\
D_{\text {ref }}= & \begin{cases}-g \sin \gamma, & \gamma<\gamma_{s 1}, \\
-k_{v 1}\left(\left(\frac{v}{r}-\frac{g}{v}\right) \cos \gamma\right)-g \sin \gamma, & \gamma_{s 2}<\gamma<\gamma_{s 1}, \\
-k_{v 2}\left(\left(\frac{v}{r}-\frac{g}{v}\right) \cos \gamma\right)-g \sin \gamma, & \gamma>\gamma_{s 2} .\end{cases}
\end{aligned}
$$

The probe can be a guide into a predetermined orbit by tracking the reference velocity $v_{\text {ref }}$ and the reference drag $D_{\text {ref }}$ through controlling the ballistic coefficient $\beta$, and the command ballistic coefficient $\beta_{\text {cmd }}$ can be achieved by the following feedback control:

$$
\beta_{\mathrm{cmd}}=\beta_{k-1}+G_{v}\left(v-v_{\mathrm{ref}}\right)+G_{D}\left(D-D_{\mathrm{ref}}\right),
$$

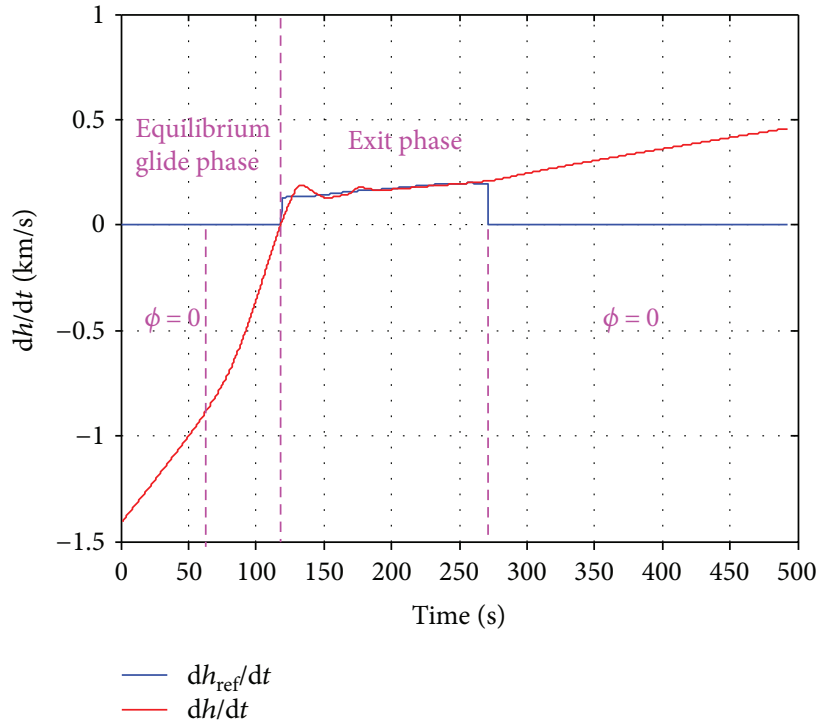

FIgURE 9: The reference altitude rate and the actual altitude rate.

where $\beta_{\mathrm{cmd}}$ is the command ballistic coefficient and $\beta_{k-1}$ is the ballistic coefficient of the previous step. After some attempts, the step size less than $0.1 \mathrm{~s}$ may achieve a satisfactory result. $G_{v}$ and $G_{D}$ are gain coefficients, respectively; all that remains is to determine $k_{v 1}, k_{v 2}, c_{v 1}$, and $c_{v 2}$.

According to the definition,

$$
k_{v}=\frac{\mathrm{d} v}{\mathrm{~d} \gamma}=\frac{\mathrm{d} v / \mathrm{d} t}{\mathrm{~d} \gamma / \mathrm{d} t}=\frac{-D-g \sin \gamma}{(v / r-g / v) \cos \gamma} .
$$

When $\gamma=0$, the altitude change rate $\dot{r}=0$, so $r_{\gamma=0}=r_{\text {min }} \approx r_{p} ;$ it can be found that $v_{\gamma=0}$ satisfies the following equation from Figure 5:

$$
v_{\gamma=0} \approx \frac{v_{0}+v_{\text {exit }}}{2} .
$$

Substituting (23) into (22),

$$
\begin{aligned}
k_{v 1} & =\frac{-D_{\gamma=0}}{\left(v_{0}+v_{\text {exit }} / 2 r_{p}\right)-\left(2 g / v_{0}+v_{\text {exit }}\right)}, \\
C_{v 1} & =\frac{v_{0}+v_{\text {exit }}}{2},
\end{aligned}
$$

where

$$
\begin{aligned}
D_{\gamma=0} & =\frac{(1 / 2) \rho\left(\left(v_{0}+v_{\text {exit }}\right) / 2\right)^{2}}{\left(\beta_{\min }+\beta_{\max }\right) / 2} \\
& =\frac{\rho_{0} \exp \left(-\left(r_{p}-R_{0}\right) / h_{s}\right)\left(\left(v_{0}+v_{\text {exit }}\right) / 2\right)^{2}}{\beta_{\min }+\beta_{\max }} .
\end{aligned}
$$

Similarly, when $\gamma=\gamma_{\text {exit }}, r=r_{\text {exit }}, v=v_{\text {exit }}$, and $D \approx 0$,

$$
\begin{gathered}
k_{v 2}=\frac{-g \sin \gamma_{\text {exit }}}{\left(\left(v_{\text {exit }} / r_{\text {exit }}\right)-\left(g / v_{\text {exit }}\right)\right) \cos \gamma_{\text {exit }}}, \\
C_{v 2}=v_{\text {exit }}-K_{v 2} \gamma_{\text {exit }} .
\end{gathered}
$$



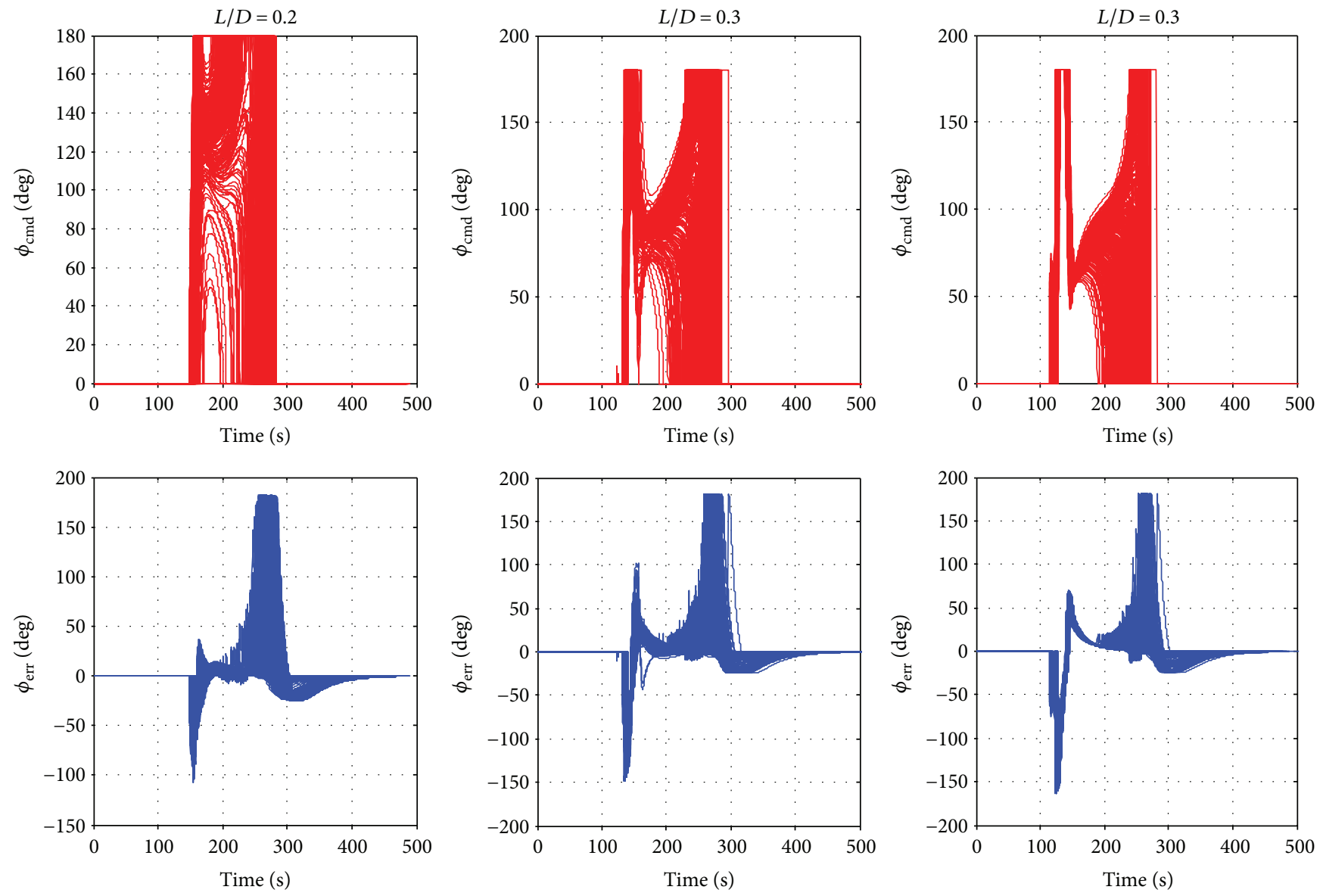

Figure 10: Bank angle and errors with different lift-drag ratios.

TABle 2: Distribution of perigee and apogee for lift modulation.

\begin{tabular}{lccc}
\hline Altitude $(\mathrm{km})$ & $L / D=0.2$ & $L / D=0.3$ & $L / D=0.4$ \\
\hline$h_{\mathrm{p}}$ minimum & -12 & -9 & -9 \\
$h_{\mathrm{p}}$ mean & 17 & 16 & 12 \\
$h_{\mathrm{p}}$ maximum & 30 & 34 & 32 \\
$h_{\mathrm{a}}$ minimum & 3180 & 3350 & 3352 \\
$h_{\mathrm{a}}$ mean & 3492 & 3421 & 3394 \\
$h_{\mathrm{a}}$ maximum & 4494 & 3508 & 3445 \\
\hline
\end{tabular}

$\gamma_{s 1}$ and $\gamma_{s 2}$ can be obtained simply:

$$
\begin{aligned}
& \gamma_{s 1}=\frac{v_{0}-C_{v 1}}{K_{v 1}}, \\
& \gamma_{s 2}=\frac{C_{v 2}-C_{v 1}}{K_{v 2}-K_{v 1}} .
\end{aligned}
$$

\section{Aerocapture Corridor}

The aerocapture corridor is an important parameter for evaluating the robustness of the guidance algorithm. Here, the corridor is defined as the span between the minimum and the maximum flight path angles for reaching the target orbit. In other words, the corridor is the boundary of the flight path angle which can ensure the probe to enter a predetermined orbit. The aerocapture corridors of the two methods are compared when the apogee height of the target orbit is about $1000 \mathrm{~km} \pm 100 \mathrm{~km}$, as shown in Figure 6. It can be found that the corridors of the two methods show a similar trend: as the initial entry velocity increases, the flight path angle gradually approaches 0 deg and the width of the corridor becomes narrower.

For the lift modulation mode, when $\phi=0^{\circ}$, the probe generates an upward lift, and the flight path angle reaches the lower boundary, and when $\phi=180^{\circ}$, the probe generates a downward lift, and the flight path angle reaches the upper boundary. The width of the corridor in the lift modulation is directly related to the lift-drag ratio, when $L / D=0.4$, the width of the corridor is more than $1.5 \mathrm{deg}$, and the corridor is reduced to a curve when $L / D=0$; although it is theoretically possible to achieve capture, because of no ballistic correction capacity, the probe cannot overcome the influence of uncertainty and error. Therefore, when using the lift modulation method, increasing the lift-drag ratio to obtain a higher design margin and robustness should be tried.

For the drag modulation mode, the width of the capture corridor is approximately proportional to the ballistic coefficient ratio.

$$
\frac{\Delta \gamma_{2}}{\Delta \gamma_{3}} \approx \frac{\beta_{4} / \beta_{2}}{\beta_{3} / \beta_{1}} .
$$



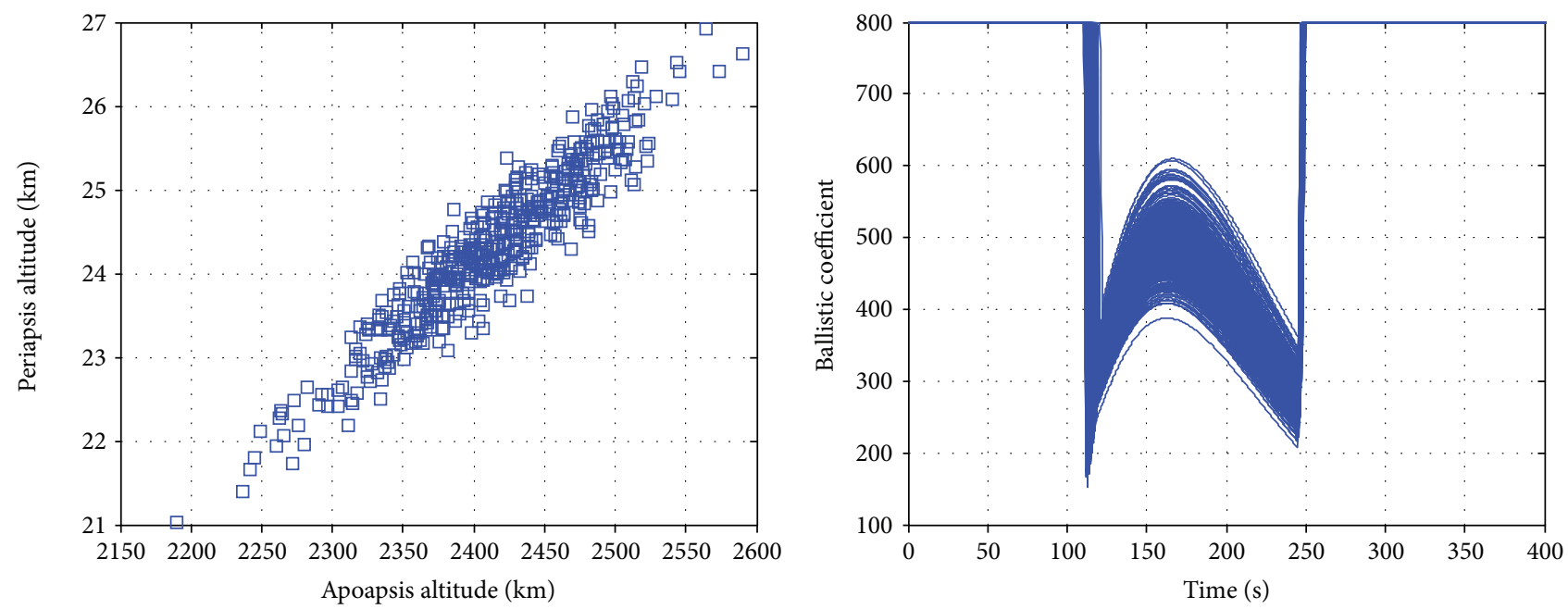

Figure 11: Aerocapture guidance error distribution and ballistic coefficient when $k_{1}=-26.0$.
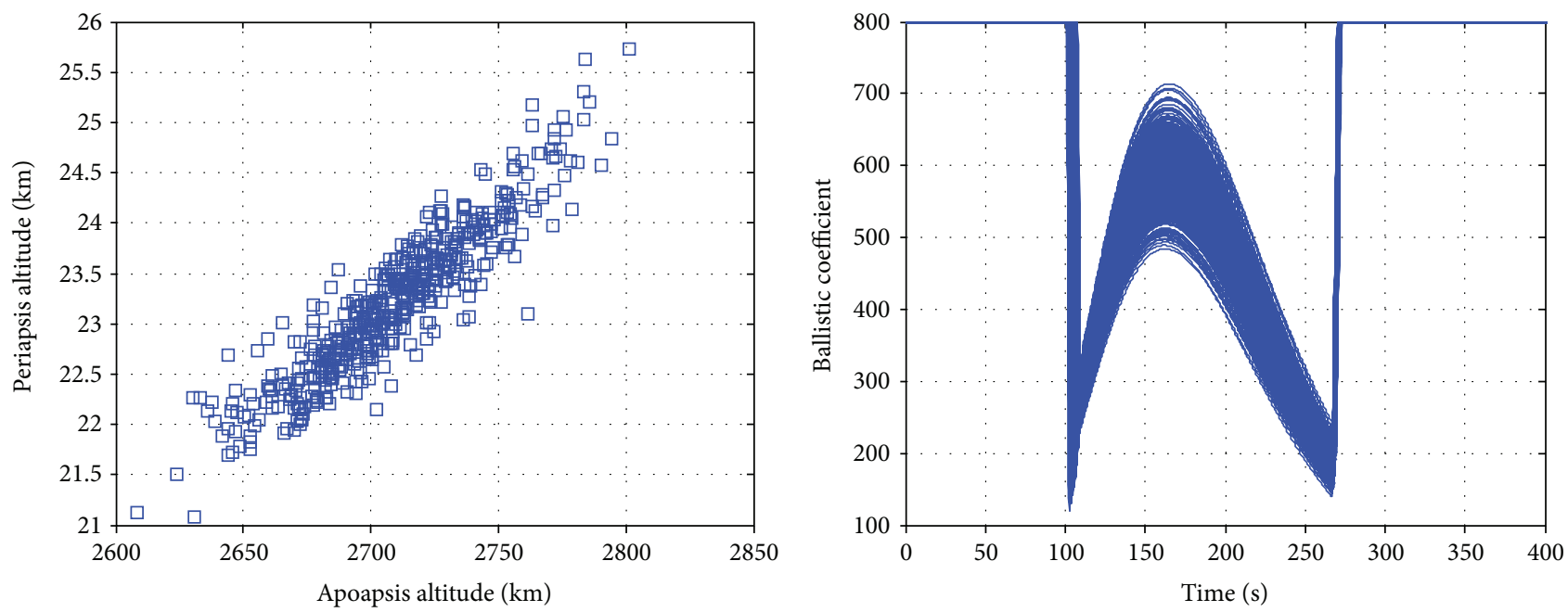

Figure 12: Aerocapture guidance error distribution and ballistic coefficient when $k_{1}=-21.6$.

If the minimum ballistic coefficient is $\beta_{1}=100$ and the maximum is $\beta_{4}=800$, when $v_{0}=5$, the width of the corridor is about $1 \mathrm{deg}$. If the minimum ballistic coefficient is $\beta_{2}=200$ and the maximum is $\beta_{3}=400$, the width of the corridor is only $0.3 \mathrm{deg}$, so this ratio between the minimum ballistic coefficient and maximum ballistic coefficient should be increased as far as possible.

\section{Guidance Performance}

5.1. Simulation Condition and Parameters. The numerical simulation is carried out for Mars exploration, which is used to verify the effectiveness of the guidance algorithm. Mars is assumed to be a uniform sphere, and its rotation effect is ignored. The gravitational constant $\mu$ is taken as $4.2828 \times 10^{4} \mathrm{~km}^{3} / \mathrm{s}^{2}$, Mars radius $R_{0}$ is taken as $3397 \mathrm{~km}$, the step size in simulation is taken as $0.1 \mathrm{~s}$, and the other parameters and initial conditions are shown in Table 1 [4].
The validity of the atmospheric model directly affects the effectiveness of the guidance algorithm performance evaluation. Therefore, the uncertainty of the atmospheric density is taken into account in the simulation. A random error with height variation is added to the exponential atmospheric density model. The variation characteristics are shown in Figure 7.

Although the model has a certain difference compared with Mars Global Reference Atmospheric Model (MarsGRAM), it can also reflect the main characteristics of the Mars atmosphere: the atmospheric density uncertainty and height are correlated with each other; the higher the height, the greater the uncertainty [20].

5.2. APC for Lift Modulation. The performance of the analytical predictor-corrector guidance algorithm based on lift modulation is shown in Figures 8-10. Table 2 shows the distribution of perigee and apogee height under different liftdrag ratios. 

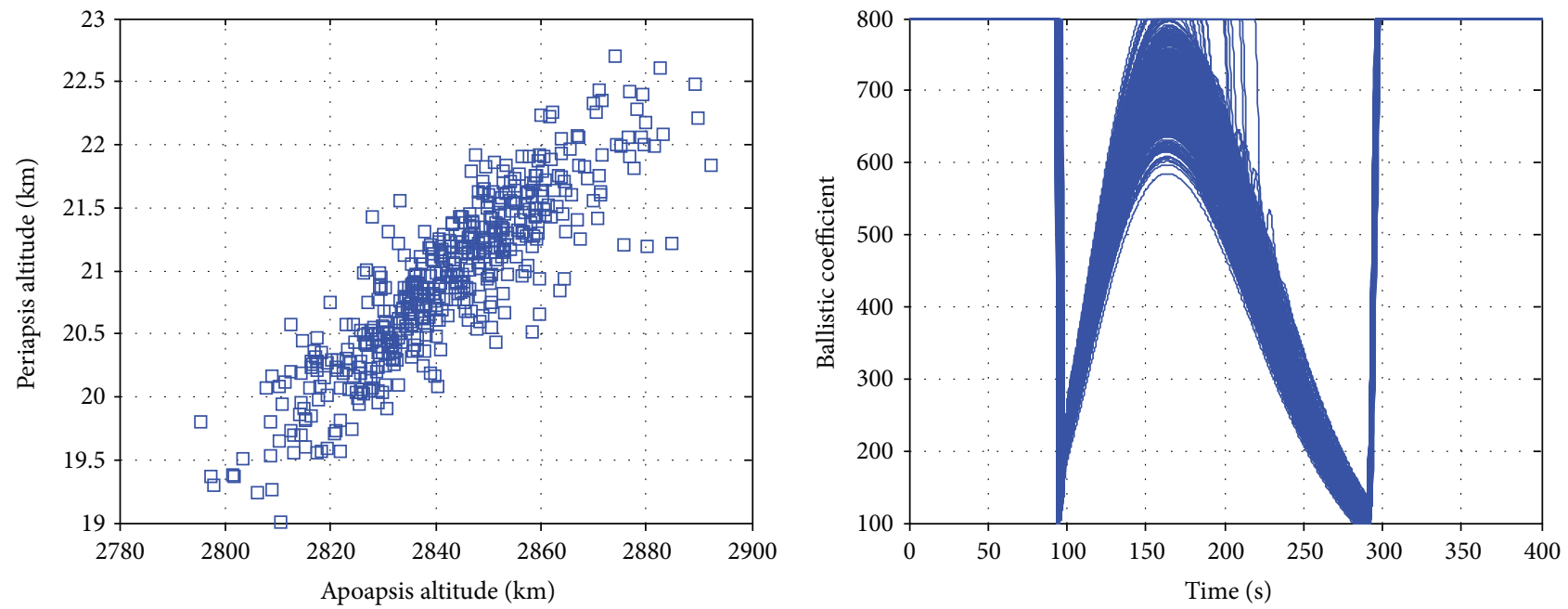

FIGURE 13: Aerocapture guidance error distribution and ballistic coefficient when $k_{1}=-18.6$.
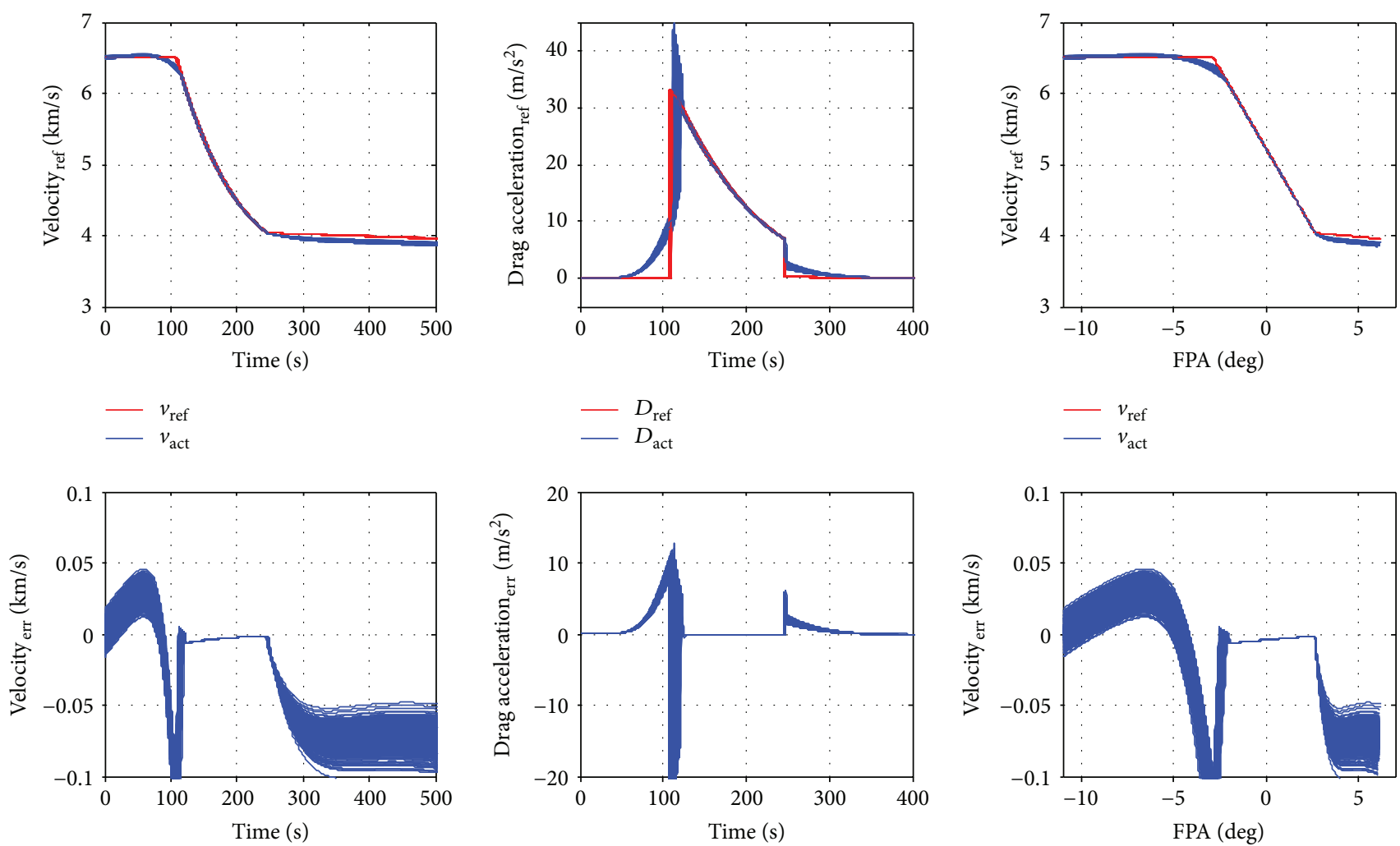

FIGURE 14: Tracking error analysis when $k_{1}=-26.0$.

It can be seen that the perigee and apogee heights are both deviated from the desired value by a constant, the deviation of perigee is about $15-20 \mathrm{~km}$, and the deviation of apogee is about $400-500 \mathrm{~km}$. By further analysis, it was found that as the height increased gradually, the ability to track the reference altitude change rate $\dot{h}_{\text {ref }}$ was weaker, so that the bank angle was fixed at $0 \mathrm{deg}$ at the end of the flight stage, as shown in Figure 9.

With the increase of the lift-drag ratio, the distribution error of the apogee gradually decreases from $1300 \mathrm{~km}$
(@L/D=0.2) to $100 \mathrm{~km}(@ L / D=0.4)$, and the distribution error of the perigee does not change significantly, and it is always maintained at $-15 \mathrm{~km} \sim 35 \mathrm{~km}$. In addition, when the lift-drag ratio is less than 0.2 , the apogee appears obvious distribution expansion phenomenon. The bank angle most of the time is in a saturated state because of less lift, the probe cannot track the reference altitude change rate $\dot{h}_{\text {ref }}$ effectively. With the increase of the lift-drag ratio, the time of the saturated state of the bank angle is shortened and the precision of guidance is gradually increased. 

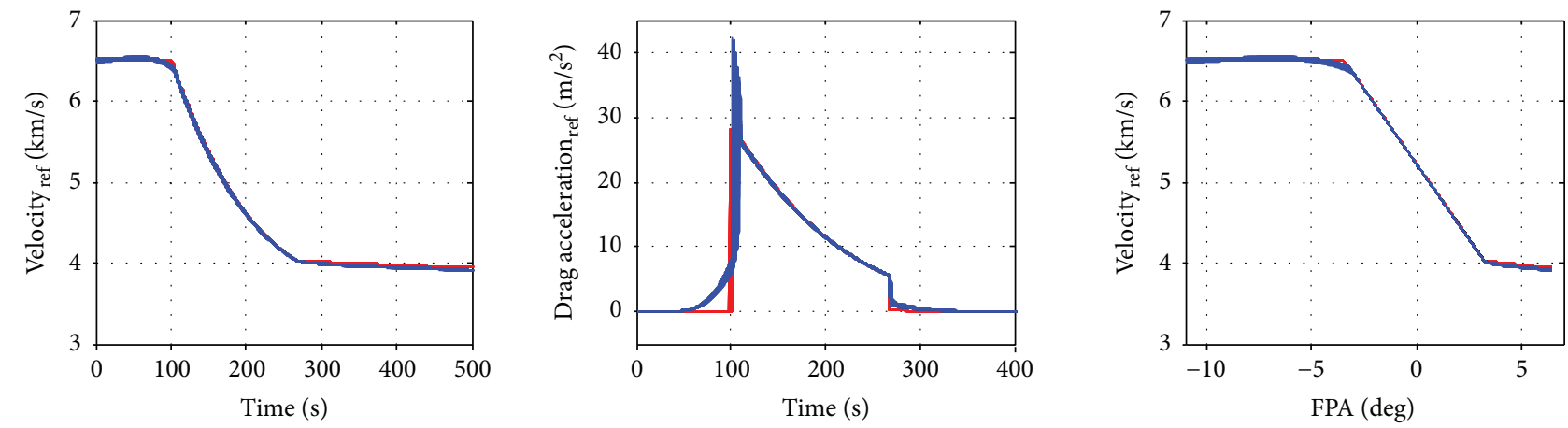

$-v_{\text {ref }}$
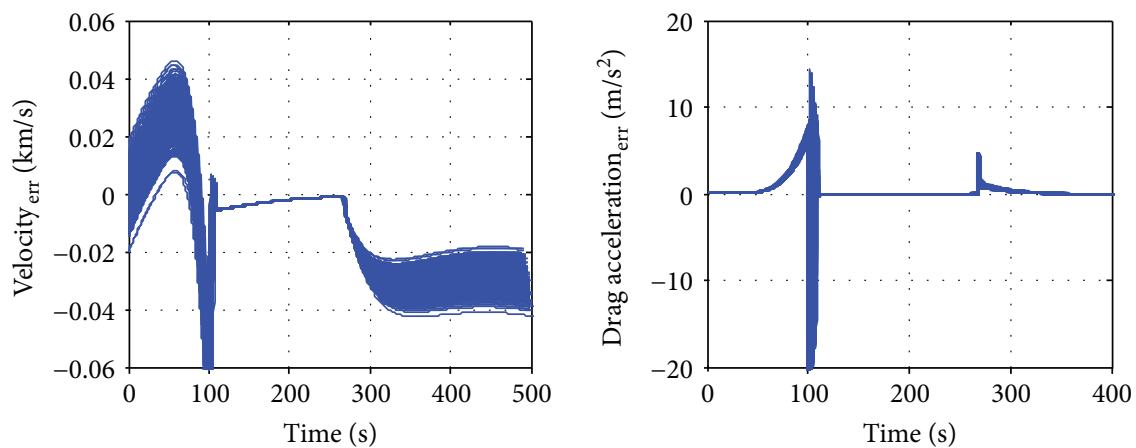

FIGURE 15: Tracking error analysis when $k_{1}=-21.6$.
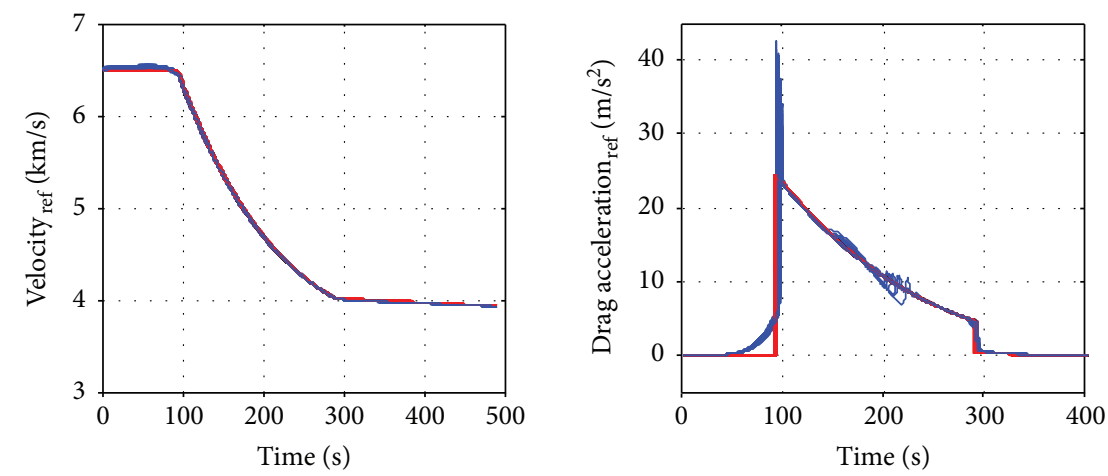

$-v_{\text {ref }}$

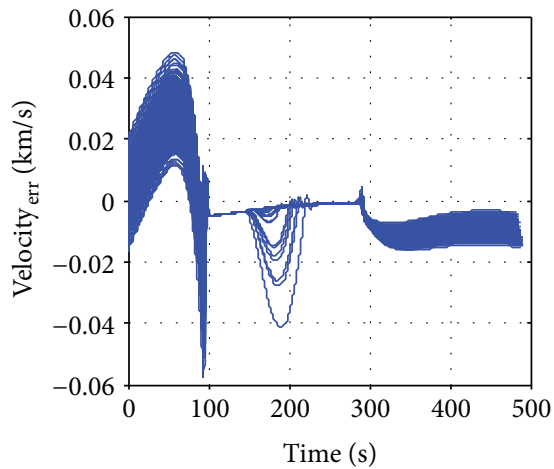

- $D_{\text {ref }}$

$-D_{\text {act }}$

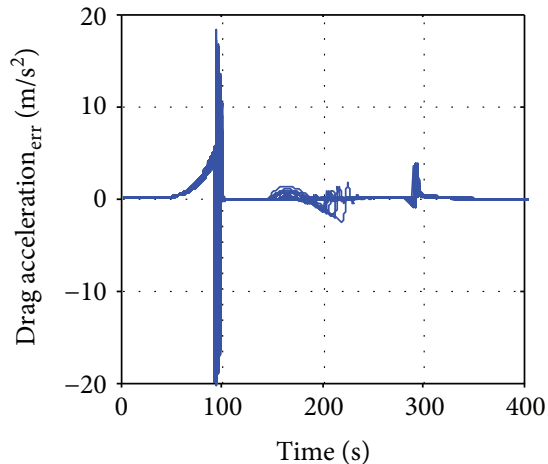

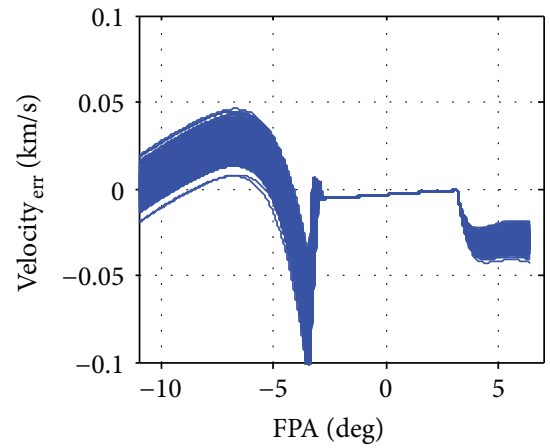

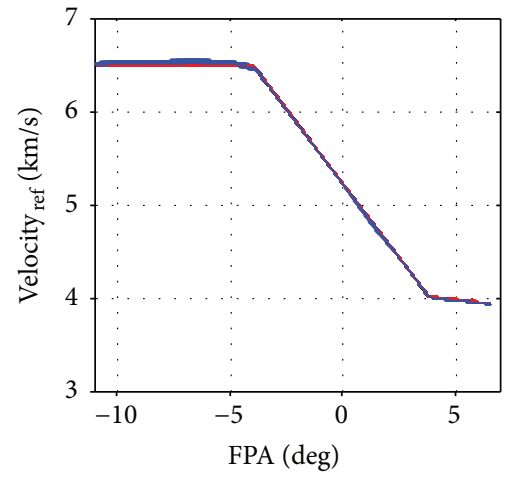

$-v_{\text {ref }}$

- $v_{\text {re }}$

$-v_{\text {act }}$

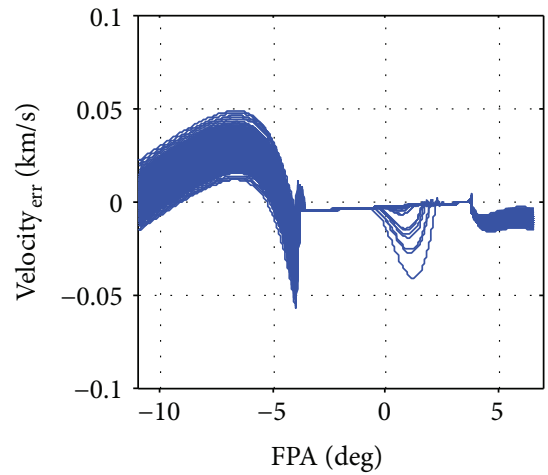

FIGURE 16: Tracking error analysis when $k_{1}=-18.6$. 
TABLE 3: Distribution of perigee and apogee for drag modulation.

\begin{tabular}{lccc}
\hline Altitude $(\mathrm{km})$ & $k_{v 1}=-26.0$ & $k_{v 2}=-21.6$ & $k_{v 3}=-18.6$ \\
\hline$h_{\mathrm{p}}$ minimum & 21 & 21.1 & 19 \\
$h_{\mathrm{p}}$ mean & 24.5 & 23.5 & 21 \\
$h_{\mathrm{p}}$ maximum & 27 & 25.7 & 22.7 \\
$h_{\mathrm{a}}$ minimum & 2191 & 2611 & 2795 \\
$h_{\mathrm{a}}$ mean & 2410 & 2714 & 2844 \\
$h_{\mathrm{a}}$ maximum & 2587 & 2804 & 2892 \\
\hline
\end{tabular}

5.3. APC for Drag Modulation. Monte Carlo simulation is carried out to analyze the performance of the proposed analytical predictor-corrector guidance algorithm for the drag modulation flight control system. The simulation results are shown in Figures 11-16. Table 3 gives the distribution of perigee and apogee heights for drag modulation with different parameters.

The simulation results show that the algorithm can effectively guide the probe to the predetermined orbit, while the apogee error is between $100 \mathrm{~km}$ and $400 \mathrm{~km}$ and the perigee error is about $5-6 \mathrm{~km}$. The guidance performance is similar to the lift modulation when $L / D>0.3$. With the value of $k_{v 1}$ increasing, the guidance performance improved gradually and the variation range of the ballistic coefficient increased gradually. The control variable $\beta$ appears saturated when $k_{v 1}=-18.6$, and there is a significant fluctuation of the tracking error (see Figure 16), but it does not affect the aerocapture guidance accuracy. This is because the velocity at the atmosphere interface is the main factor affecting the aerocapture accuracy. Although the tracking error of the intermediate process will affect the exit state, it can be compensated during the subsequent flight, so there is no significant influence on the final trajectory.

In addition, there is a constant deviation of the apogee which is associated with the guidance parameter. The reason is similar to the lift modulation guidance algorithm. When the probe is about to exit the atmosphere, the drag acceleration reduces to a low level resulting in the loss of control ability which leads to the guidance bias.

\section{Conclusion}

In this paper, the aerocapture guidance algorithms for lift modulation and drag modulation are studied around Mars exploration, and the guidance performance and corridor are analyzed, respectively. An analytical predictor-corrector guidance algorithm based on drag modulation is proposed. A piecewise linear function between velocity and flight path angle is established by appropriate approximations and assumptions, and then the state at the atmosphere interface can be predicted by an analytical method; therefore, aerocapture guidance can be realized by feedback control. The simulation results show that the guidance algorithm is accurate and robust, which can effectively overcome the influence of atmospheric density error, aerodynamic parameter error, and initial state uncertainty.

\section{Conflicts of Interest}

All the authors do not have any possible conflicts of interest.

\section{Acknowledgments}

This study was supported by the Basic Scientific Research Fund of National Defense (no. 2016110C019) and Civil Aerospace Preresearch program (no. D030106).

\section{References}

[1] J. L. Hall, M. A. Noca, and R. W. Bailey, "Cost-benefit analysis of the aerocapture mission set," Journal of Spacecraft and Rockets, vol. 42, no. 2, pp. 309-320, 2005.

[2] J. M. Salotti and E. Suhir, "Manned missions to Mars: minimizing risks of failure," Acta Astronautica, vol. 93, pp. 148161, 2014.

[3] J. M. Salotti, "Robust, affordable, semi-direct Mars mission," Acta Astronautica, vol. 127, pp. 235-248, 2016.

[4] D. W. Way, R. W. Powell, A. Chen et al., "Mars Science Laboratory: entry, descent and landing system performance," in 2007 IEEE Aerospace Conference, Big Sky, MT, USA, March 2007.

[5] A. D. McRonald, "A light-weight inflatable hypersonic drag device for planetary entry," in Association Aeronautique de France Conference, pp. 16-18, Arcachon, France, March 1999.

[6] S. Reza, R. Hund, F. Kustas et al., "Aerocapture inflatable decelerator (AID) for planetary entry," in 19th AIAA Aerodynamic Decelerator Systems Technology Conference and Seminar: American Institute of Aeronautics and Astronautics, Williamsburg, VA, USA, 2007.

[7] A. M. D. Cianciolo, J. L. Davis, D. R. Komar et al., "Entry, Descent and Landing Systems Analysis Study," Tech. Rep. NASA TM-2010-216720, 2010.

[8] R. R. Rohrschneider and R. D. Braun, "Survey of ballute technology for aerocapture," Journal of Spacecraft and Rockets, vol. 44, no. 1, pp. 10-23, 2007.

[9] Z. R. Putnam and R. D. Braun, "Drag-modulation flightcontrol system options for planetary aerocapture," Journal of Spacecraft and Rockets, vol. 51, no. 1, pp. 139-150, 2014.

[10] P. Lu, "Entry guidance: a unified method," Journal of Guidance, Control, and Dynamics, vol. 37, no. 3, pp. 713-728, 2014.

[11] J. Masciarelli, S. Rousseau, H. Fraysse, and E. Perot, "An analytic aerocapture guidance algorithm for the Mars sample return orbiter," in Atmospheric Flight Mechanics Conference, pp. 2000-4116, Denver, CO, USA, August 2000.

[12] E. Perot, H. Fraysse, S. Rousseau, and J. Berges, "Comparison of an analytic predictor-corrector and a terminal point controller for the Mars sample return aerocapture," in Association A'eronautique et Astronautique de France, Paper AAAF, pp. 14-67, March 2001.

[13] J. F. Hamel and J. Lafontaine, "Improvement to the analytical predictor-corrector guidance algorithm applied to Mars aerocapture," Journal of Guidance, Control, and Dynamics, vol. 29, no. 4, pp. 1019-1022, 2006.

[14] A. Kozynchenko, "Development of optimal and robust predictive guidance technique for Mars aerocapture," Aerospace Science and Technology, vol. 30, no. 1, pp. 150-162, 2013.

[15] S. Rousseau, An Energy Controller Aerocapture Guidance Algorithm for the Mars Sample Return Orbiter, Paper AAS, 2001. 
[16] J. Berges, S. Rousseau, and E. Perot, “A numerical predictorcorrector guidance algorithm for the Mars sample return aerocapture," in Association A'eronautique et Astronautique de France, pp. 14-66, Paper AAAF, 2001.

[17] T. Ro and E. Queen, "Study of martian aerocapture terminal point guidance," in 23rd Atmospheric Flight Mechanics Conference, pp. 1998-4571, Boston, MA, USA, 1998.

[18] S. Rousseau, E. Perot, C. Graves, J. Masciarelli, and E. Queen, "Aerocapture guidance algorithm comparison campaign," in AIAA/AAS Astrodynamics Specialist Conference and Exhibit, pp. 5-8, Monterey, CA, USA, August 2002.

[19] K. Medlock and L. Gates, Theory and Applications of Ballute Aerocapture and Dual-Use Ballute Systems for Exploration of the Solar System, Purdue University, West Lafayette, IN, USA, 2009.

[20] C. G. Justus, "Mars Global Reference Atmospheric Model for mission planning and analysis," Journal of Spacecraft and Rockets, vol. 28, no. 2, pp. 212-221, 1991. 


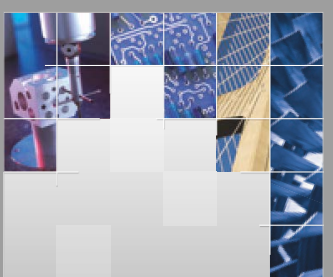

\section{Enfincering}
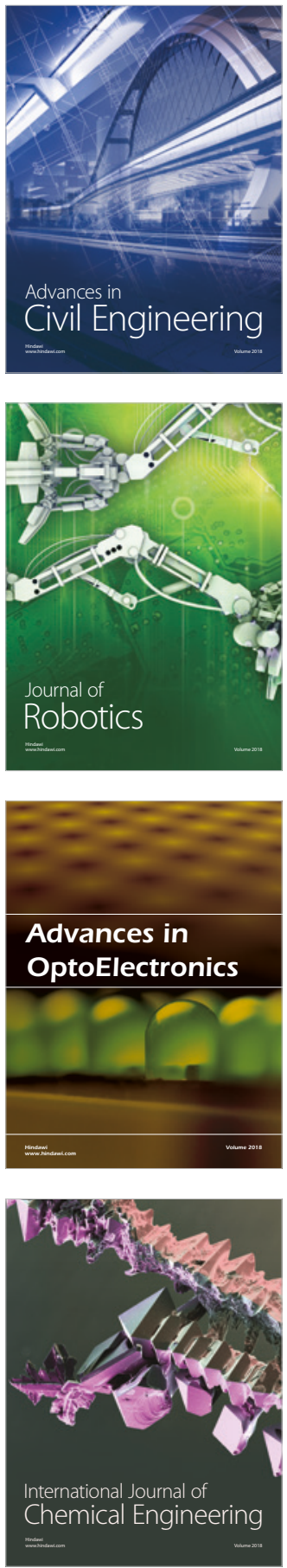

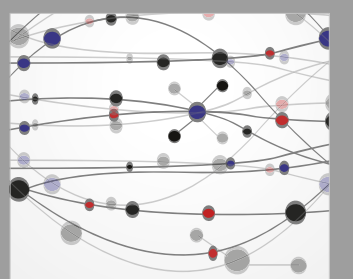

\section{Rotating \\ Machinery}

The Scientific World Journal

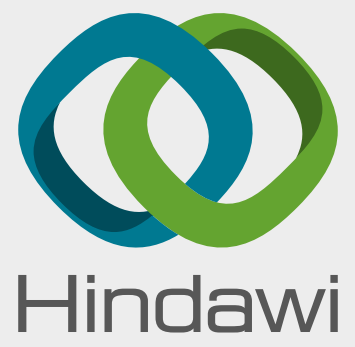

Submit your manuscripts at

www.hindawi.com
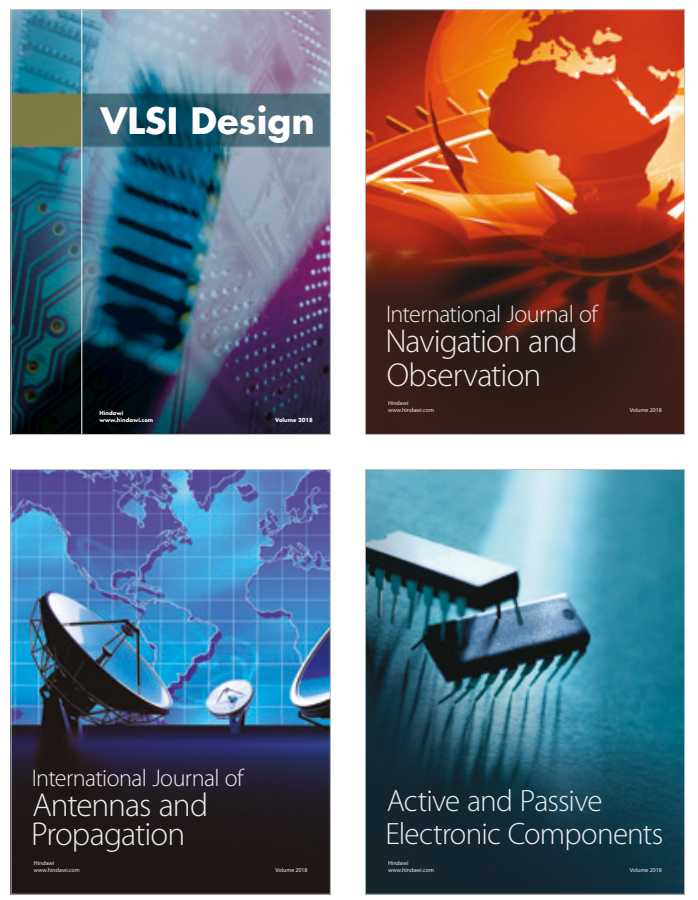
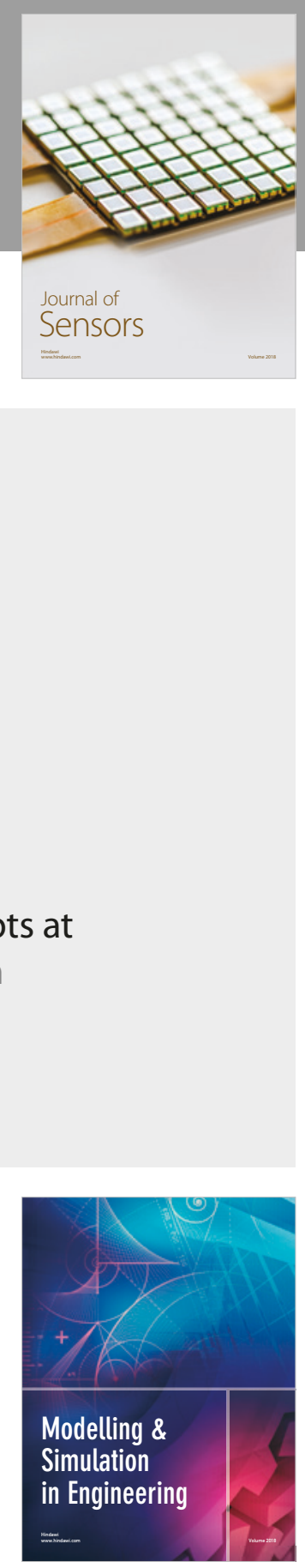

\section{Advances \\ Multimedia}
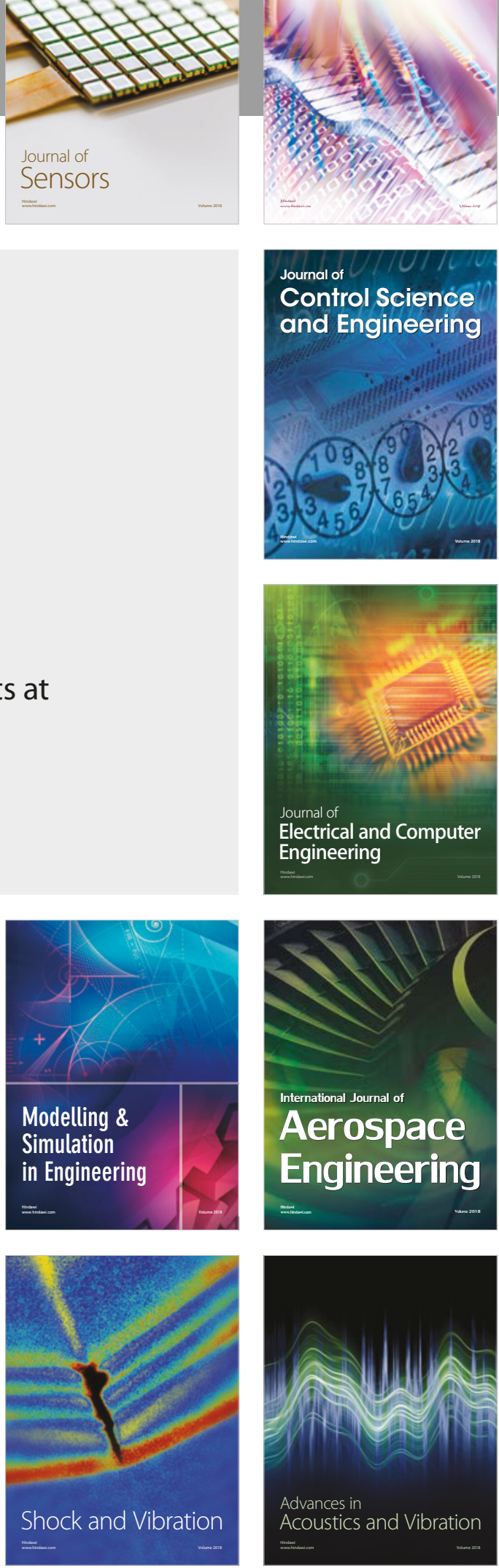